\title{
BMJ Open Healthcare utilisation and costs for temporomandibular disorders: a descriptive, cross-sectional study
}

\author{
Hyejin Seo, ${ }^{1}$ Boyoung Jung (D) , ${ }^{2,3}$ Jiyoon Yeo, ${ }^{4}$ Koh-Woon Kim, ${ }^{5}$ Jae-Heung Cho, ${ }^{5}$ \\ Yoon Jae Lee (D) , ${ }^{4}$ In-Hyuk Ha (i) ${ }^{4}$
}

To cite: Seo H, Jung B, Yeo J, et al. Healthcare utilisation and costs for temporomandibular disorders: a descriptive, crosssectional study. BMJ Open 2020;10:e036768. doi:10.1136/ bmjopen-2020-036768

- Prepublication history and additional material for this paper are available online. To view these files, please visit the journal online (http://dx.doi. org/10.1136/bmjopen-2020036768).

Received 03 January 2020 Revised 18 August 2020 Accepted 21 September 2020

\section{Check for updates}

(c) Author(s) (or their employer(s)) 2020. Re-use permitted under CC BY-NC. No commercial re-use. See rights and permissions. Published by BMJ.

${ }^{1}$ Korean rehabilitation medicine, Jaseng Hospital of Korean Medicine, Seoul, South Korea ${ }^{2}$ Department of Health Administration, Hanyang Women's University, Seoul, South Korea

${ }^{3}$ Jaseng Spine and Joint Research Institute, Jaseng Medical Foundation, Gangnamdaero, Gangnam-gu, Seoul, Republic of Korea

${ }^{4}$ Department of Clinical

Research, Jaseng Spine and Joint Research Institute, Jaseng Medical Foundation, Seoul,

South Korea

${ }^{5}$ Department of Korean

Rehabilitation Medicine, College of Korean Medicine, Kyung Hee University, Seoul, South Korea

Correspondence to

In-Hyuk Ha;

hanihata@gmail.com

\section{ABSTRACT}

Objective Temporomandibular joint disorder (TMD) requires long-term management and can be a financial burden for patients. Here, we investigated the treatment received by people diagnosed with TMD and its relevant costs.

Design A descriptive, cross-sectional study.

Setting and participants We performed secondary data analysis of health insurance claims data provided by the Health Insurance Assessment and Review (HIRA) of the Republic of Korea. We reviewed the records of 10041 patients who were diagnosed with TMD and who utilised outpatient healthcare service at least once between January and December 2017.

Primary and secondary outcome measures Data on use of medical services, hospitalisations, sociodemographic factors, treatment and medication were retrieved and analysed. Cost was defined as the cost of care incurred by a health insurance beneficiary at a care facility.

Results We reported the characteristics as medians, frequencies and percentages and found that most TMD patients were outpatients, women (58.9\%) and in their 20 s (46.4\%). For visit type, $85.9 \%$ of all patients had an outpatient dental medical visit, with most visiting dental clinics and dental hospitals. Western medicine (WM; $9.8 \%$ ) was prescribed more often, followed by Korean medicine (KM; 8.2\%). The median expense per patient was highest among those in their 20s (58.00, 23.90, 53.40, 65.90 US\$ for overall, WM, dental medicine (DM) and $\mathrm{KM}$, respectively). Consultation fees accounted for the greatest percentage (42.8\%) of DM and WM care expenses, while injection/non-surgical intervention fees accounted for the greatest percentage of KM care expenses. The most commonly used treatments for TMD were temporomandibular joint stimulation therapy (51.1\%) and acupuncture (19.9\%), considered as the most basic care for TMD. Psychosomatic agents (86.4\%) were the most commonly used medications in outpatients. Conclusions While people with TMD most commonly received temporomandibular stimulation therapy, the costs and duration of treatment varied significantly for these patients.

\section{INTRODUCTION}

The temporomandibular joint (TMJ) is one of the most frequently used joints in the

\section{Strengths and limitations of this study}

- A major strength of this study lies in its large sample size, which was based on nationwide health insurance claims data.

- This is the first study to investigate the current status of temporomandibular joint disorder in Korea, including the use of Western medicine, dental medicine and Korean medicine.

- Because inpatient admissions were considered to be due to major injuries or invasive surgery and the number of inpatients was small, we were unable to analyse inpatient data in detail.

- Non-covered care and over-the-counter drugs were not included in the Health Insurance Review and Assessment-National Patient Sample claims data, and the use of secondary data such as claims data may lead to diagnostic inaccuracies.

- Because we used the only 2017 claim data, patients could not be followed-up over time.

human body. ${ }^{1}$ It is a complex synovial joint enveloped by a joint capsule and consists of articulations between the mandibular fossa and articular tubercle of the temporal bone and the articular process of the mandible. ${ }^{2}$ Temporomandibular disorders (TMD) are diseases involving structural or functional impairments of TMJ-related structures, ${ }^{3}$ and they may be accompanied by various symptoms including myofascial tenderness and pain, headache, joint noises, trismus and even tinnitus. ${ }^{4}$ Although the prevalence of TMD varies depending on the target population, definition and research methodology, it remains high at $11 \%-50 \% .^{5}$ TMD is also known to frequently affect women and people in their 20s-40s. ${ }^{6}$ A study based on the Korea National Health and Nutrition Examination Survey reported a prevalence of $3.1 \%$ among TMD patients with persistent symptoms for $\geq 3$ months. ${ }^{7}$ According to an analysis of 2010 2015 health insurance payout data by the National Health Insurance Service (NHIS), the number of patients who received care 
with TMD as the main diagnosis increased by $40.5 \%$ from 250000 in 2010 to 350000 in $2015 .^{8}$

TMD is perceived not as an acute or fatal disorder but as a self-limiting, chronic and complex dental disease with diverse symptoms caused by several factors. ${ }^{9}$ Chronic TMD is also known to have strong correlations with other medical conditions including headache, low back pain, joint pain, abdominal pain and mental disorders. ${ }^{10-12}$ Therefore, TMD requires long-term management, along with consideration to various pain-related conditions as well as mental health issues. For this reason, TMD patients are likely to be financially burdened in the long term. In fact, prior studies have reported that insurance claim costs incurred by TMD patients are nearly twice as those incurred by non-TMD patients. ${ }^{13}$

Despite the difficult reality faced by TMD patients, research on medical costs and specific medical utilisation regarding TMD is lacking. Only one study has investigated the healthcare utilisation by TMD patients in Korea, ${ }^{14}$ but it did not assess the medical cost for each claimed item nor captured the specific details of care. Given this dearth of information, our study aimed to examine the current status of TMD treatment and its relevant costs in Korea, by analysing claims data from the Health Insurance Review and Assessment (HIRA) National Patient Sample (NPS) data set.

\section{METHODS}

\section{Data source}

We analysed health insurance claims data from the 2017 HIRA-NPS data set. Health insurance claims data are generated when healthcare facilities make insurance benefit claims with the HIRA after providing medical services to patients. Claims data contain massive amounts of diverse information including details of care (eg, treatment, procedure, examination, prescription), diagnosis, insurer's payment, patient's out-of-pocket cost, patient population demographics and information about the care provider, which are highly valuable for healthcare research. The HIRA provides annual sample data that can be extracted via random stratified sampling to ensure researchers' access to data and convenience. The extracted secondary data exclude personally identifiable and corporate information from the raw data and contain insurance claims over a 1-year period from the date of care initiation for the corresponding year. Patients who utilised medical services over a 1-year period were selected using a systematic, stratified sampling method, by sex and age group (5-yearly units) and their details of care and prescriptions are provided. ${ }^{15}$ As of $2017,3 \%$ of the entire patient population, which was about 1.45 million people, were included in the data set. ${ }^{16}$

In some countries where traditional medicine is practiced as a whole medical system, such as with the traditional Chinese medicine or Ayurveda, both conventional medicine and traditional medicine exist as independent medical systems. ${ }^{17}$ South Korea also has a unique healthcare system where Korean traditional medicine and Western medicine (including dental medicine) exist on equal terms with exclusive practice boundaries. ${ }^{18}$ Moreover, South Korea does not exploit the family physician system, which means that the patients are free to select their primary care centres among a multitude of clinics and hospitals.

\section{Patient and public involvement}

There was no direct patient or public involvement in this review.

\section{Study design and population}

We performed a cross-sectional, descriptive study analysing patients who were diagnosed with TMD in Korea and utilised medical services at least once between January and December 2017. While previous studies have used the Research Diagnostic Criteria for TMD ${ }^{19}$ or selfreported surveys ${ }^{20}$ to diagnose TMD, limited studies have used ICD codes in administrative data. In this study, our research team operationally defined TMD as cases with an International Statistical Classification of Disease and Related Health Problems, 10th revision (ICD-10) code of K07.6 (TMJ disorders) or S03.4 (sprain and strain of jaw) as the main diagnosis under outpatient care.

Claims data provided by the HIRA included raw data on treatment prescriptions for all patients who received medical services over the course of 1 year. The raw data did not contain personal and corporate information. Because the claims were submitted monthly, charges in the statement reflected up to 1 month of information. In other words, patients who had been hospitalised for $>1$ month would have been charged separately for each month. In such cases, errors such as overestimation of the number of inpatients and underestimation of medical expenses might occur when performing statistical analyses. Therefore, data on hospitalisation episodes, which involved collecting and calibrating several claims charged monthly for one consecutive medical practice, were used. In this study, separate claim forms of hospitalised patients were bundled into one hospitalisation episode. Variables used in the episode creating process included claims identification key, patient identification key, insurance type, main diagnostic code, treatment type, treatment start date and treatment end date.

Figure 1 shows the study participant selection process. Of the 35765 claims of patients who visited the hospital with a K07.6 or S03.4 diagnostic code in 2017, a total of 11 608 claims whose secondary diagnostic code was not null were excluded. Additionally, 17 claims with zero total costs or missing cost data were also excluded, as well as 14 claims in which the number of days of visit was 0 . Therefore, a total of 24126 claims and 10041 patients were included in the final analysis. Among 10141 patients, there were only nine inpatient admissions, which were considered to be due to major injuries or invasive surgery. Because of such small sample size, these data might not accurately represent the actual number of TMD inpatients, so we 


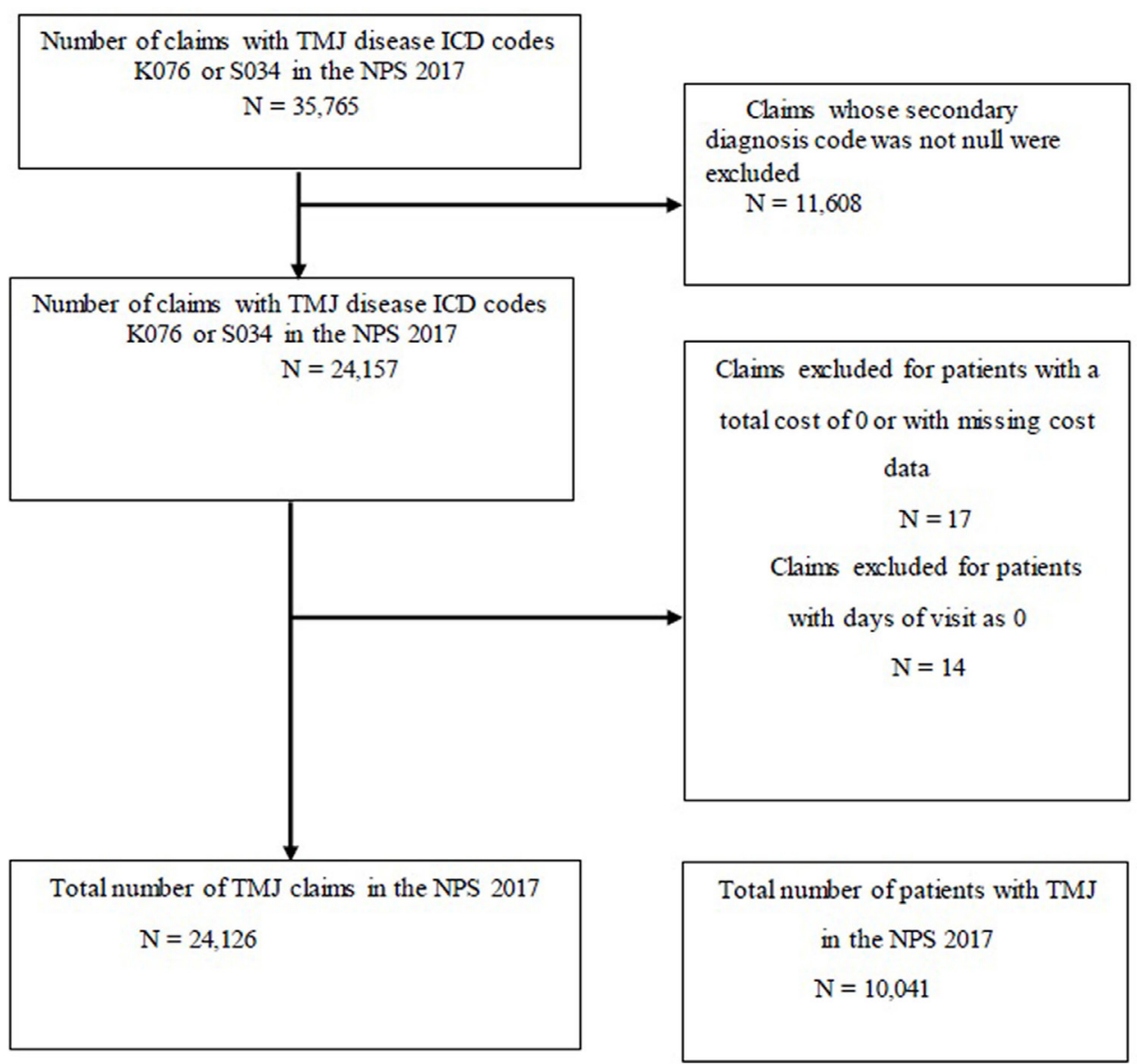

Figure 1 Participant flow diagram. ICD-10, International Statistical Classification of Disease and Related Health Problems, 10th revision; NPS, National Patient Sample; TMJ, temporomandibular joint.

did not analyse inpatient data in detail. Moreover, a single patient can be included as both inpatient and outpatient.

\section{Data analysis}

TMD patients were classified by age (eight categories of 10-yearly units, from 0 to 9 years to $\geq 70$ years), sex, payer type (health insurance, medical aid and other), surgery, visit type (Western, dental and Korean medicine inpatient or outpatient; public health centre inpatient or outpatient), medical specialty and type of healthcare institution, and the frequency of each characteristic was analysed. In Korea, the payment system is fee-for-service based on the National Health Insurance (NHI) system. According to the HIRA guidelines under the Ministry of Health and Welfare (MOHW) ${ }^{15}$ the total cost is based on the following 11 categories: outpatient visit (consultation), hospital admission, medication, injection/ non-surgical intervention, anaesthesia, physiotherapy, psychotherapy, treatment and surgery, examination and radiographic evaluation/intervention. In this study, among the 11 categories, the number of 'uses of special equipment' was very small; therefore, only the 10 practices were used as the criteria. Previous studies using HIRA-NPS data in Korea followed these 10 classification criteria. ${ }^{21}{ }^{22}$ Cost was defined as the cost of care incurred by a health insurance beneficiary at a care facility, which is the sum of the NHIS-covered cost and the patient's outof-pocket cost. This was determined by review of the total cost of care claimed by a care facility.

We analysed the frequencies of billing codes for procedures such as injection/non-surgical interventions, physiotherapy and surgery, and listed them in order from the highest to the lowest frequency. We only included items determined to be directly relevant to TMD care on discussion and review among our team.

Drug codes assigned during inpatient and outpatient care were classified according to the MOHW protocol and were listed according to frequency of use for TMD treatment. Each drug was classified according to Anatomical Therapeutic Chemical (ATC) codes within the MOHW classification criteria shown in online supplemental table 1, to additionally analyse frequently used codes. Published in 1976, the ATC Classification System has been used to classify drugs and medical products and is being managed by the WHO Collaborating Centre for Drug Statistics Methodology. ${ }^{22}$

\section{Statistical analyses}

The patients' demographic characteristics and medical service-related details, including payer type, surgery, facility visit type, medical specialty, medical institution type, medication, injection, anaesthesia, physiotherapy, 
Table 1 General medical service use for patients with temporomandibular joint disorder in Korea

\begin{tabular}{|c|c|c|c|c|c|c|c|c|}
\hline Type of visit & & $\begin{array}{l}\text { Number of } \\
\text { patients } *\end{array}$ & $\begin{array}{l}\text { Number of } \\
\text { cases* }\end{array}$ & $\begin{array}{l}\text { Total } \\
\text { expense† }\end{array}$ & $\begin{array}{l}\text { Per-patient } \\
\text { expense† }\end{array}$ & $\begin{array}{l}\text { Per-case } \\
\text { expense† }\end{array}$ & $\begin{array}{l}\text { Average } \\
\text { days in } \\
\text { care }\end{array}$ & $\begin{array}{l}\text { Average } \\
\text { days in } \\
\text { visits } \$\end{array}$ \\
\hline \multirow[t]{3}{*}{ Total } & Total & 10041 & 24126 & 721447.5 & 71.9 & 29.9 & 2.4 & 2.4 \\
\hline & K076 & 9571 & 22915 & 696483.4 & 72.8 & 30.4 & 2.4 & 2.4 \\
\hline & S034 & 576 & 1211 & 24964.1 & 43.3 & 20.6 & 2.1 & 2.1 \\
\hline \multirow[t]{2}{*}{ Inpatients } & Total & 9 & 9 & 4750.5 & 527.8 & 527.8 & 7.4 & 2.2 \\
\hline & S034 & 1 & 1 & 140.9 & 140.9 & 140.9 & 1.0 & 1.0 \\
\hline \multirow[t]{3}{*}{ Outpatients } & Total & 10040 & 24117 & 716697.1 & 71.4 & 29.7 & 2.4 & 2.4 \\
\hline & K076 & 9570 & 22907 & 691873.8 & 72.3 & 30.2 & 2.4 & 2.4 \\
\hline & S034 & 575 & 1210 & 24823.2 & 43.2 & 20.5 & 2.1 & 2.1 \\
\hline
\end{tabular}

*If a patient had multiple diagnostic codes, the most frequent code was indicated. Only one person had both K076 and S034 codes. †Amount presented in US\$. 1 US\$=1086 KRW (average rate in December 2017).

$\ddagger$ Average days in care: the number of total treatment days denoted in the claims statement including days with drug prescription without medical treatment.

$\S$ Average days of visits: the number of outpatient visits or the number of inpatient care days indicated in the claims statement.

psychotherapy, procedure/surgery, examination and radiographic evaluation/intervention, were reported as frequencies and percentages according to inpatient/ outpatient status, particularly whether the patient was an Western medicine outpatient, dental medicine outpatient or Korean medicine outpatient. For medical expenses, the medical cost per category, percentage of costs for each category and medical cost per claim or per patient were computed. Analyses were conducted using the SAS package V.9.4 (SAS Institute, Cary, NC, USA).

\section{RESULTS}

\section{General medical services use for TMD patients in Korea}

There were two main diagnostic codes for TMD (K076 and S034), and the number of patients, number of claims, total cost, per-patient cost, per-claim cost, average days in care and average number of hospital visits were compared between the inpatient and outpatient groups (table 1). In 2017, a total of 10041 patients received care for TMD as the main diagnosis. A total of 10041 patients, including nine inpatients, received outpatient care and those with the code K076 accounted for most of our sample. The number of patients, total cost, per-patient cost, per-claim cost, average days in care and average days of visit were all higher with the code K076 than with the code S034.

The total cost was 721447.5 US\$ (average conversion rate in December 2017: 1 US $\$=1086$ KRW). From this cost, 4750.5 US\$ was spent on inpatient care and the rest on outpatient care. The cost of inpatient care was 7.4 times higher than that for outpatient care, at an average of 71.4 and 527.8 US\$ for outpatients and inpatients, respectively. Only one patient was hospitalised under the code S034. Among those with $\mathrm{S} 034$ as the main diagnosis, the average days in care and the average days of visit were 2.1 times higher for outpatients.

\section{General characteristics}

The characteristics of the TMD patients are shown in table 2A,B. The majority of patients were in their 20s, and this age group also had the highest total number of days of care. TMD frequency tended to decrease with advancing age after the age of 30-39 years. At three visits, the average number of days in care was highest among patients aged $\geq 70$ years. It was lowest among patients aged $0-9$ years at 1.6 days. Average expense was highest and lowest among patients aged $20-29$ and $\geq 70$ years, respectively. The greatest expense was 1584.7 US\$ among patients in their $30 \mathrm{~s}$.

Most of the patients were women (58.9\%), who had a higher average number of days in care than men (table 2A). Women also incurred more expenses than men did when the mean expenses were compared by sex (95.50 vs 73.00 US\$), and the maximum expense was incurred by a female patient (1584.7 US\$). There were differences in mean expense per patient (male: 73.0 US \$ vs female: 95.3 US\$) and between sexes. Data on insurance type, surgery, visit type, medical specialty and medical institution type are shown in table 2B.

\section{Distribution of medical expenditures}

The distribution of medical expenditures in TMD according to medical practice type is detailed in table 3 . Outpatient visit expenses accounted for the greatest proportion of all expenditures $(35.4 \%)$, followed by treatment and surgery $(20.5 \%)$, radiographic evaluation/intervention (18.1\%) and injection/non-surgical intervention (16.3\%). Outpatient visit fees accounted for $40.6 \%, 38.2 \%$ and $24.2 \%$ of all medical expenses in Western, dental and Korean medicine, respectively.

From the total medical expenditure of 643867.2 US\$ spent by the entire patient population, $42.8 \%$ was spent on outpatient visit fees. Outpatient visit fees accounted for 
Table 2A General characteristics of patients with diagnostic codes indicating temporomandibular joint disorder in Korea

\begin{tabular}{|c|c|c|c|c|c|c|c|c|c|}
\hline \multirow[b]{2}{*}{ Category } & & \multicolumn{2}{|l|}{ Patient } & \multicolumn{6}{|c|}{ Visit count } \\
\hline & & $\begin{array}{l}\text { Total N } \\
(10041)\end{array}$ & $\%$ & $\begin{array}{l}\text { Total N } \\
(24 \text { 126) } \\
\end{array}$ & $\%$ & Mean & SD & Min & Max \\
\hline \multirow[t]{8}{*}{ Age } & $0-9$ & 99 & 1.0 & 158 & 0.7 & 1.6 & 2.5 & 1 & 19 \\
\hline & $10-19$ & 1813 & 18.1 & 4373 & 18.1 & 2.4 & 3.1 & 1 & 29 \\
\hline & $20-29$ & 2737 & 27.3 & 6200 & 25.7 & 2.3 & 3.0 & 1 & 48 \\
\hline & 30-39 & 1570 & 15.6 & 3482 & 14.4 & 2.2 & 2.8 & 1 & 31 \\
\hline & $40-49$ & 1329 & 13.2 & 3028 & 12.6 & 2.3 & 3.1 & 1 & 50 \\
\hline & $50-59$ & 1137 & 11.3 & 3086 & 12.8 & 2.7 & 6.0 & 1 & 108 \\
\hline & $60-69$ & 782 & 7.8 & 2103 & 8.7 & 2.7 & 4.2 & 1 & 51 \\
\hline & $\geq 70$ & 574 & 5.7 & 1696 & 7.0 & 3.0 & 5.2 & 1 & 63 \\
\hline \multirow[t]{2}{*}{ Sex } & Male & 4128 & 41.1 & 8587 & 35.6 & 2.1 & 3.1 & 1 & 108 \\
\hline & Female & 5913 & 58.9 & 15539 & 64.4 & 2.6 & 4.0 & 1 & 108 \\
\hline \multirow[t]{3}{*}{ Payer type* } & $\mathrm{NHI}$ & 9790 & 97.5 & 23583 & 97.7 & 2.4 & 3.7 & 1 & 108 \\
\hline & MD & 255 & 2.5 & 522 & 2.2 & 2.0 & 2.3 & 1 & 16 \\
\hline & Others & 4 & 0.0 & 21 & 0.1 & 5.3 & 4.3 & 1 & 11 \\
\hline \multirow[t]{2}{*}{ Surgery† } & No & 9970 & 99.3 & 24034 & 99.6 & 2.4 & 3.7 & 1 & 108 \\
\hline & Yes & 71 & 0.7 & 92 & 0.4 & 1.3 & 0.9 & 1 & 6 \\
\hline \multirow[t]{8}{*}{ Visit type } & WM IP & 1 & 0.0 & 1 & 0.0 & 1.0 & - & 1 & 1 \\
\hline & WM OP & 980 & 9.8 & 1491 & 6.2 & 1.5 & 1.8 & 1 & 22 \\
\hline & DM IP & 7 & 0.1 & 7 & 0.0 & 1.0 & - & 1 & 1 \\
\hline & DM OP & 8627 & 85.9 & 18565 & 77.0 & 2.2 & 2.8 & 1 & 108 \\
\hline & PHC IP & - & - & - & - & - & - & - & - \\
\hline & PHC OP & 15 & 0.1 & 33 & 0.1 & 2.2 & 1.5 & 1 & 6 \\
\hline & KM IP & 1 & 0.0 & 1 & 0.0 & 1.0 & - & 1 & 1 \\
\hline & KM OP & 825 & 8.2 & 4028 & 16.7 & 4.9 & 7.7 & 1 & 108 \\
\hline \multirow{6}{*}{$\begin{array}{l}\text { Medical } \\
\text { specialty }\end{array}$} & $C D$ & 4309 & 42.9 & 7604 & 31.5 & 1.8 & 2.6 & 1 & 108 \\
\hline & OM & 2133 & 21.2 & 5990 & 24.8 & 2.8 & 3.1 & 1 & 45 \\
\hline & OMS & 2566 & 25.6 & 4250 & 17.6 & 1.7 & 2.0 & 1 & 48 \\
\hline & IKM & 432 & 4.3 & 2234 & 9.3 & 5.2 & 9.0 & 1 & 108 \\
\hline & AMM & 356 & 3.5 & 1620 & 6.7 & 4.6 & 5.8 & 1 & 50 \\
\hline & OS & 405 & 4.0 & 648 & 2.7 & 1.6 & 1.9 & 1 & 22 \\
\hline \multirow{8}{*}{$\begin{array}{l}\text { Medical } \\
\text { institution type }\end{array}$} & $\mathrm{TH}$ & 714 & 7.1 & 1705 & 7.1 & 2.4 & 4.9 & 1 & 107 \\
\hline & Hospital & 93 & 0.9 & 128 & 0.5 & 1.4 & 1.4 & 1 & 11 \\
\hline & Clinic & 823 & 8.2 & 1260 & 5.2 & 1.5 & 1.8 & 1 & 22 \\
\hline & DM hospital & 1669 & 16.6 & 3958 & 16.4 & 2.4 & 2.4 & 1 & 25 \\
\hline & DM clinic & 6656 & 66.3 & 12995 & 53.9 & 2.0 & 2.5 & 1 & 48 \\
\hline & KM hospital & 70 & 0.7 & 222 & 0.9 & 3.2 & 3.6 & 1 & 22 \\
\hline & KM clinic & 757 & 7.5 & 3809 & 15.8 & 5.0 & 8.0 & 1 & 108 \\
\hline & Others & 30 & 0.3 & 49 & 0.2 & 1.6 & 1.2 & 1 & 6 \\
\hline
\end{tabular}

${ }^{*}$ Others, national free medical treatment or veteran healthcare.

†Surgery was counted as 'once' if a patient had at least one surgery performed.

$\mathrm{AMM}$, acupuncture and moxibustion medicine; $\mathrm{CD}$, conservative dentistry; DM, dental medicine; GH, general hospital; IKM, internal Korean medicine; IP, inpatient; KM, Korean medicine; LCH, long-term care hospital; MD, medicaid; NHI, national health insurance; OM, oral medicine; OMS, oral and maxillofacial surgery; OP, outpatient; OS, orthopaedic surgery; PHC, public health centre; TH, tertiary hospital; WM, western medicine. 


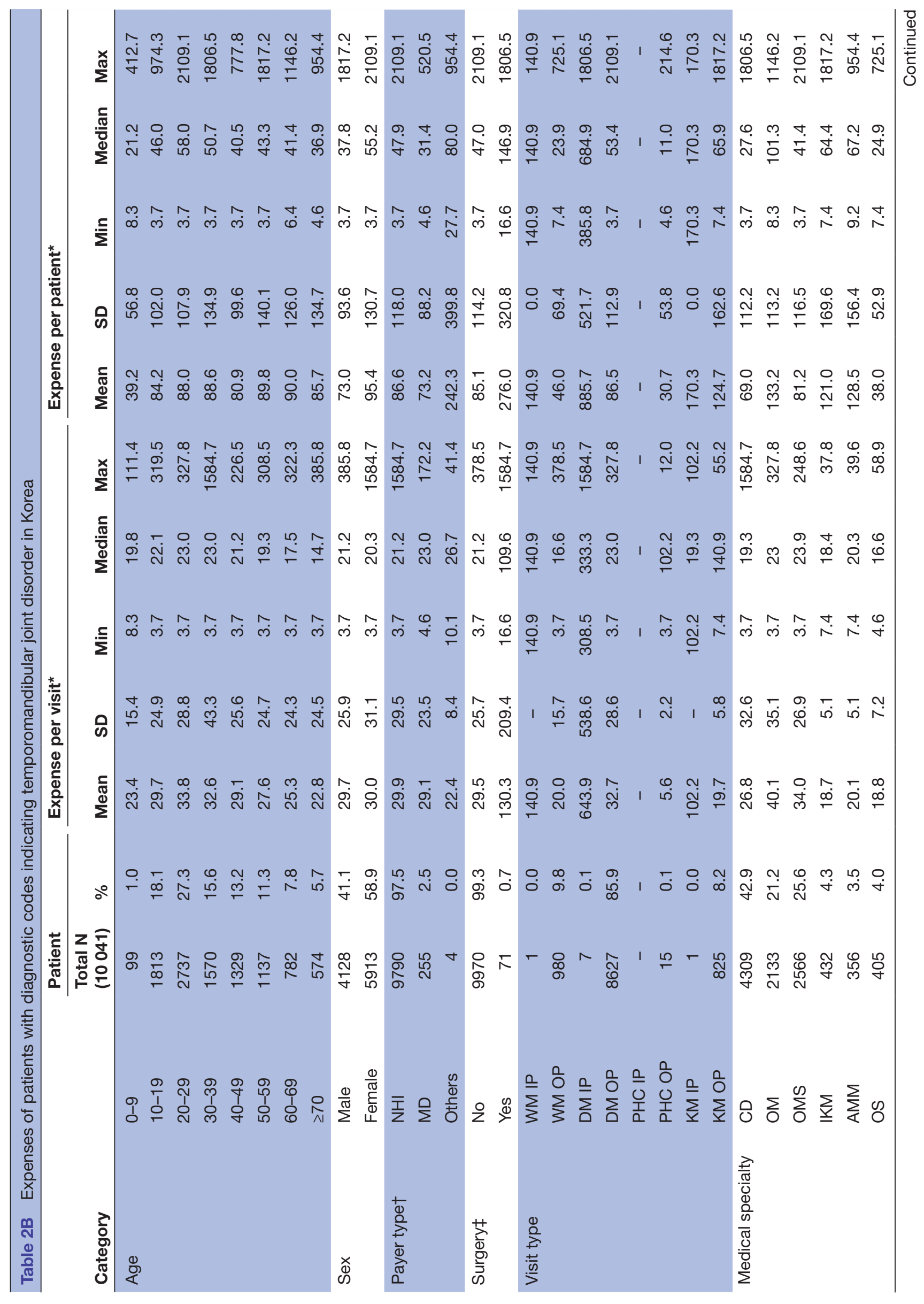



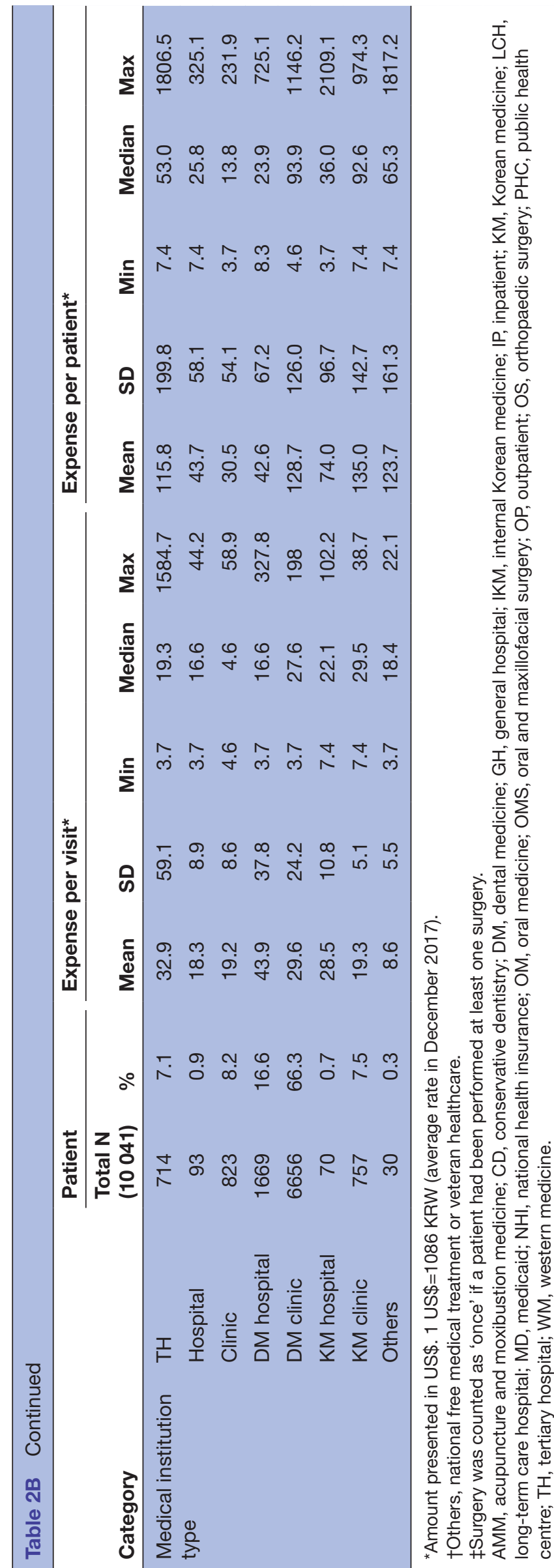

the majority of Western and dental medicine expenses, at $66.9 \%$ and $41.3 \%$ of all medical expenditures, respectively, while injection/non-surgical intervention fees accounted for the majority (54.7\%) of Korean medicine expenses. Hospitalisation, anaesthesia, and medication accounted for the lowest percentages of medical expenditure.

While results for outpatients were only slightly different from those for all patients, inpatient results showed that injection/non-surgical intervention fees accounted for the greatest percentage $(27.9 \%)$ of costs. In Western medicine inpatients, consultation fees accounted for the vast majority of the medical expenditure (90.6\%). In Korean medicine inpatient care, hospitalisation fees accounted for $51.3 \%$ of total expenditures, which differed from inpatient care expenditures in Western medicine or dentistry, where the percentage spent on hospitalisation fees was very low or negligible.

\section{Usual care of TMD}

The frequencies of claims for treatments according to usual care practice classifications in both outpatients and inpatients are shown in table 4 . The most frequently performed treatment in outpatient care was TMJ stimulation $(\mathrm{n}=18616,51.1 \%)$. In Western medicine outpatient care, superficial heat therapy and subcutaneous or intramuscular injection were the most common forms of physiotherapy $(\mathrm{n}=511,30.7 \%)$ and injection/non-surgical practices $(\mathrm{n}=184,64.8 \%)$, respectively. There were no claim codes for surgery in Western medicine outpatient care. In dental outpatient care, TMJ stimulation $(n=18$ $616,85.1 \%)$ and occlusal adjustment $(\mathrm{n}=71,55.5 \%)$ were the most frequently performed physiotherapy and injection/non-surgical interventions, respectively. The only surgery code claimed in outpatient dental care was TMJ arthrocentesis $(n=45)$. Finally, general acupuncture $(\mathrm{n}=7228,58.4 \%)$ was the most frequently performed intervention in Korean medicine outpatient care.

Among all inpatient claims, the most frequently performed treatment was continuous intravenous injection $(\mathrm{n}=55,73.3 \%)$. In Western medicine inpatient care, bolus intravenous injection was performed only once. In dental inpatient care, physiotherapy was not performed, while continuous intravenous injection was the most frequently performed injection/non-surgical intervention. The only surgical code claimed in dental inpatient care was TMJ arthrocentesis $(n=8)$. Finally, acupuncture was performed four out of six times in Korean medicine inpatient care.

\section{Medication prescribed for temporomandibular joint disorder}

Table 5 lists the number of days of prescription by TMD drug according to the MOHW classification. The most common prescriptions in overall care and in dental outpatient care were psychosomatic drugs (86.4\%). Antipyretic analgesic agents accounted for $50.9 \%$ of all Western medicine prescriptions. In dental inpatient care, oxygen was the most commonly prescribed $(26.6 \%)$. 


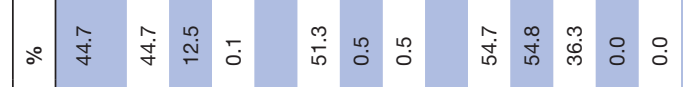

우웅

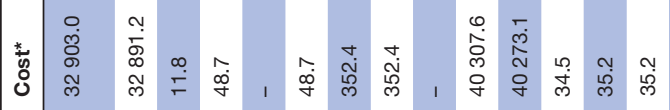

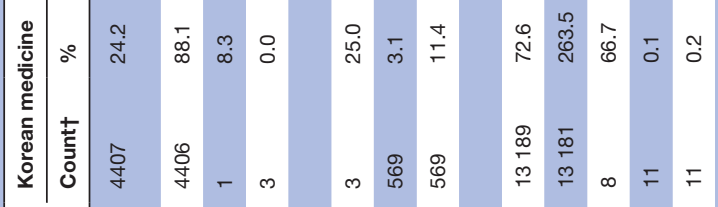

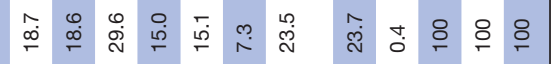

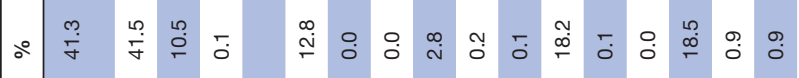

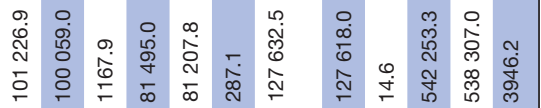

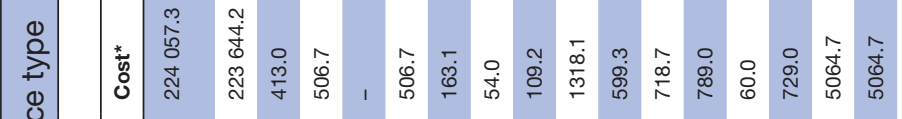

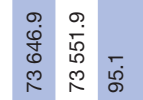

용

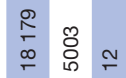

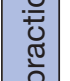

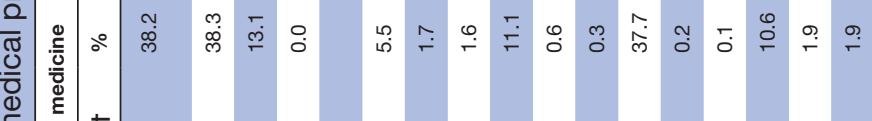

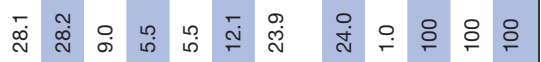

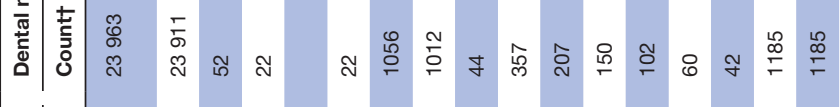

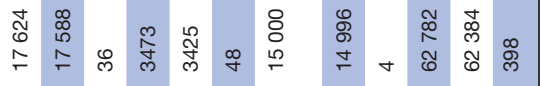

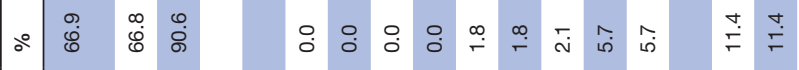

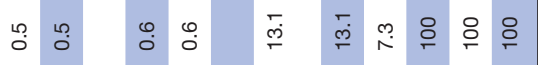

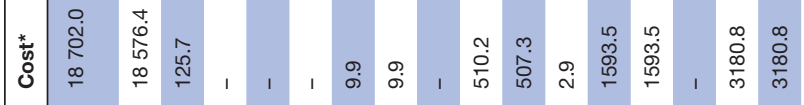

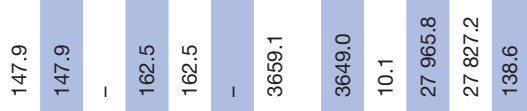

|

ֻ

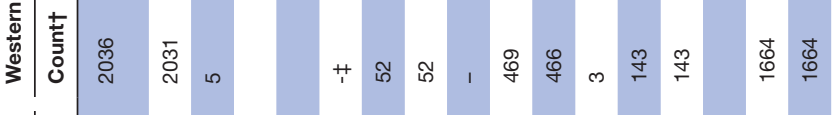

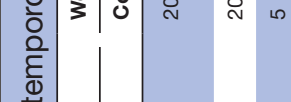

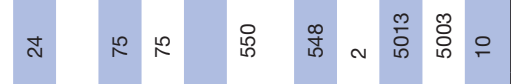

它

ㅎํ

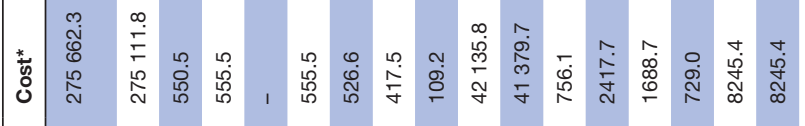

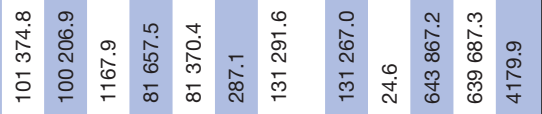

$\therefore$ 过

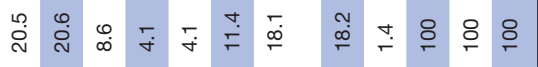

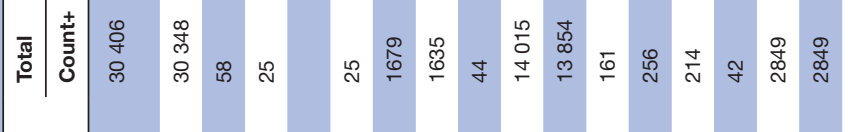

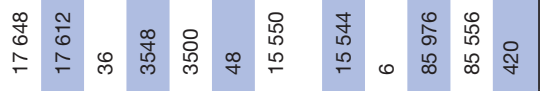


Table 4 Usual care of patients with temporomandibular joint disorder

Outpatient total (items 1, 2 and 3)

\begin{tabular}{|c|c|c|c|c|}
\hline Classification & Treatment & Code name & Count (n) & $\%$ \\
\hline \multirow[t]{9}{*}{ All usual care practices } & TMJ stimulation & U2381, U2382, U2383 & 18616 & 51.1 \\
\hline & Acupuncture & $\begin{array}{l}40011,40012,40030,40050 \\
40060,40070,40080,40120\end{array}$ & 7228 & 19.9 \\
\hline & Hot and cold meridian therapy & $40700,40701,40702$ & 2093 & 5.7 \\
\hline & Spray and stretch therapy & MX032 & 1986 & 5.5 \\
\hline & Electroacupuncture & 40091 & 1103 & 3.0 \\
\hline & Moxibustion & 40304, 40305, 40306, 40307 & 781 & 2.1 \\
\hline & Superficial heat therapy & MM010, MM015 & 686 & 1.9 \\
\hline & Manipulation therapy & MX036 & 642 & 1.8 \\
\hline & \multicolumn{2}{|r|}{ 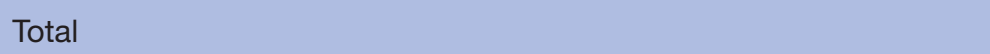 } & 36408.5 & 100 \\
\hline
\end{tabular}

(1) Western medicine outpatient

\begin{tabular}{|c|c|c|c|c|}
\hline \multirow[t]{9}{*}{ Physiotherapy } & Superficial heat therapy & MM015 & 511 & 30.7 \\
\hline & Deep heat therapy & MM020 & 415 & 24.9 \\
\hline & Laser therapy & MM085 & 266 & 16.0 \\
\hline & ICT & MM080 & 86 & 5.2 \\
\hline & Infrared ray irradiation & MM300 & 73 & 4.4 \\
\hline & Massage therapy & MM090 & 15 & 0.9 \\
\hline & UV ray irradiation & MM030 & 8 & 0.5 \\
\hline & Cold therapy-cold pack & MM011 & 6 & 0.4 \\
\hline & Others & $\begin{array}{l}\text { MX121, MM131, KK010, LA341, } \\
\text { LA232, U4900, N0771, KK090, } \\
\text { KK061, KK062, KK020, KK052 }\end{array}$ & 5 & 0.3 \\
\hline \multirow{6}{*}{$\begin{array}{l}\text { Injection and non-surgical } \\
\text { intervention }\end{array}$} & $\begin{array}{l}\text { Cranial nerve or its peripheral } \\
\text { branch block }\end{array}$ & LA341, LA232 & 54.5 & 19.2 \\
\hline & $\begin{array}{l}\text { Closed reduction of TMJ } \\
\text { dislocation }\end{array}$ & U4900, N0771 & 18 & 6.3 \\
\hline & Intraarticular injection & KK090 & 15 & 5.3 \\
\hline & Perineural injection & KK061 & 4.5 & 1.6 \\
\hline & Others & KK062, KK020, KK052 & 8 & 2.8 \\
\hline & Total & & 284 & 100 \\
\hline \multicolumn{5}{|c|}{ (2) Dental medicine outpatient } \\
\hline
\end{tabular}


Table 4 Continued

Outpatient total (items 1, 2 and 3)

\begin{tabular}{|c|c|c|c|c|}
\hline Classification & Treatment & Code name & Count (n) & $\%$ \\
\hline & Manipulation therapy & MX036 & 642 & 2.9 \\
\hline & Deep heat therapy & MM020 & 182.5 & 0.8 \\
\hline & Superficial heat therapy & MM015 & 156.5 & 0.7 \\
\hline & TENS & MM070 & 134 & 0.6 \\
\hline & Simple therapeutic exercise & MM101 & 81 & 0.4 \\
\hline & Laser therapy & MM085 & 38 & 0.2 \\
\hline & Infrared ray irradiation & МM300 & 27 & 0.1 \\
\hline & ICT & MM080 & 9 & 0.0 \\
\hline & Total & & 21872 & 100 \\
\hline \multirow{7}{*}{$\begin{array}{l}\text { Injection and non-surgical } \\
\text { intervention }\end{array}$} & Occlusal adjustment & U2290 & 71 & 55.5 \\
\hline & $\begin{array}{l}\text { Closed reduction of TMJ } \\
\text { dislocation }\end{array}$ & U4900, N0771 & 22 & 17.2 \\
\hline & Intraarticular injection & KK090 & 15 & 11.7 \\
\hline & $\mathrm{SC}$ or intravenous injection & KK010 & 13 & 10.2 \\
\hline & Continuous intravenous injection & KK052 & 2 & 1.6 \\
\hline & Others & $\begin{array}{l}\text { C8020, KK020, LA341, U2352, } \\
\text { U4830, UX044 }\end{array}$ & 5 & 3.9 \\
\hline & Total & & 128 & 100 \\
\hline \multirow[t]{2}{*}{ Surgery } & TMJ arthrocentesis & UX044 & 45 & 100 \\
\hline & Total & & 45 & 100 \\
\hline \multicolumn{5}{|c|}{ (3) Korean medicine outpatient } \\
\hline \multirow[t]{2}{*}{ Acupuncture } & Acupuncture & $\begin{array}{l}40011,40012,40030,40050 \\
40060,40070,40080,40120\end{array}$ & 7228 & 58.4 \\
\hline & Electroacupuncture & 40091 & 1103 & 8.9 \\
\hline Physiotherapy & Hot and cold meridian therapy & 40700, 40701, 40702 & 2093 & 16.9 \\
\hline Moxibustion & Moxibustion & 40304, 40305, 40306, 40307 & 781 & 6.3 \\
\hline \multirow[t]{2}{*}{ Cupping } & Cupping & $\begin{array}{l}\text { 10312, 40313, 40321, 40322, } 40 \\
323\end{array}$ & 1181 & 9.5 \\
\hline & Total & & 12386 & 100 \\
\hline
\end{tabular}

Inpatient (items 4, 5 and 6)

$\begin{array}{lllll}\text { Classification } & \text { Treatment } & \text { Code name } & \text { Count (n) } & \% \\ \text { Physiotherapy, injection and } & \text { Continuous intravenous injection } & \text { KK051, KK052, KK053, KK054 } & 55 & 73.3 \\ \text { non-surgical intervention, } & \text { TMJ arthrocentesis } & \text { UX044 } & 8 & 10.7 \\ \text { surgery, } & \text { Acupuncture } & 40 \text { 012 to } 40080 & 4 & 5.3 \\ \text { acupuncture, } & \text { KK020 injection } & \text { KK010 } & 3 & 4.0 \\ \text { moxibustion, } & \text { SC or intravenous injection } & \text { KK090 } & 2 & 2.7 \\ \text { cupping } & \text { Intraarticular injection } & 40 \text { 091 } & 1 & 1.3 \\ & \text { Electroacupuncture } & 40701 & 1 & 1.3 \\ & \text { Hot and cold meridian therapy } & 1 & 1.3 \\ & \text { Total } & & 75 & 100 \\ \text { (4) Western medicine inpatient } & & & 1 & 100 \\ \text { Injection and non-surgical } & \text { IV injection } & \text { KK020 } & 1 & 100 \\ \text { intervention } & \text { Total } & & & \\ \text { (5) Dental medicine inpatient } & & & \end{array}$


Table 4 Continued

\begin{tabular}{|c|c|c|c|c|}
\hline \multicolumn{5}{|c|}{ Outpatient total (items 1, 2 and 3) } \\
\hline Classification & Treatment & Code name & Count (n) & $\%$ \\
\hline \multirow{5}{*}{$\begin{array}{l}\text { Injection and non-surgical } \\
\text { intervention }\end{array}$} & Continuous intravenous injection & KK051, KK052, KK053, KK054 & 55 & 91.7 \\
\hline & SC or intravenous injection & KK010 & 2 & 3.3 \\
\hline & IV injection & KK020 & 2 & 3.3 \\
\hline & Intraarticular injection & KK090 & 1 & 1.7 \\
\hline & Total & & 60 & 100 \\
\hline \multirow[t]{2}{*}{ Surgery } & TMJ arthrocentesis & UX044 & 8 & 100 \\
\hline & Total & & 8 & 100 \\
\hline \multicolumn{5}{|c|}{ (6) Korean medicine inpatient } \\
\hline \multirow[t]{2}{*}{ Acupuncture } & Acupuncture & 40012 to 40080 & 4 & 66.7 \\
\hline & Electroacupuncture & 40091 & 1 & 16.7 \\
\hline \multirow[t]{2}{*}{ Physiotherapy } & Hot and cold meridian therapy & 40701 & 1 & 16.7 \\
\hline & Total & & 6 & 100 \\
\hline
\end{tabular}

ICT, interferential current therapy; IM, intramuscular; SC, subcutaneous; TENS, transcutaneous electrical nerve stimulation; TMJ, temporomandibular joint.

Online supplemental table 1 shows the analysis of ATC codes specifically used within the top 10 MOHW classification categories. The most frequently used ATC codes among psychosomatic, radiopharmaceutical and antipyretic analgesic drugs in dental outpatient care were diazepam, technetium $(99 \mathrm{mTc})$ pertechnetate and paracetamol (acetaminophen), respectively. In Western medicine outpatient care, antipyretic analgesic agents were the most frequently used drug class, but the most frequently used ATC code was diazepam ( $\mathrm{n}=117.5)$ among psychosomatic drugs, and tramadol $(\mathrm{n}=94)$ among antipyretic analgesic agents.

\section{DISCUSSION}

In this cross-sectional, descriptive study, a total of 10041 patients received care for TMD as the main diagnosis (K076 and S034). The number of patients, total cost, per-patient cost, per-claim cost, average days in care and average days of visit were all higher with the code K076 (2.4) than with the code S034 (2.1). As shown in online supplemental table 2 , the average number of visits of 2.4 was the result reflecting the maximum number of visits of $>100$. Therefore, most patients visited once a year, while some patients visited more than 100 times.

TMD patients were more likely to be women, to be aged between 20 and 29 years, and to receive outpatient care. Among outpatients, TMJ stimulation and general acupuncture were the most frequently performed treatments, and psychosomatic drugs were the most frequently prescribed medications for TMD. Finally, consultation fees accounted for the greatest percentage of expenses for dental and Western medicine, while injection/nonsurgical intervention fees accounted for the greatest percentage of expenses for Korean medicine. With 98\% of the Korean population enrolled in the NHI system, its claims data can be considered as nationally representative. This study is the first to analyse medical costs and usual care for TMD in Korea using the 2017 HIRA-NPS health insurance claims data.

A prior study reported that the preferred response to TMD is conservative treatment, ${ }^{23}$ but the specific computation of the frequency of each treatment modality was lacking. Furthermore, in a special healthcare environment such as Korea, where Korean medical care is commonly used, analysing healthcare utilisation pertaining to TMD—which falls under dental, Western and Korean medicine-would add to the significance of the study.

In this study, we analysed the treatments most frequently used by clinicians for each TMD-related disease. These findings are useful in providing evidence for usual care and establishing treatment guidelines. We analysed the 2017 HIRA claims data for patients who received care for TMD in 2017, and we examined the status for codes K076 and S034 separately. Outpatient care accounted for the majority of both diagnostic codes, presumably because TMD patients generally have mild conditions with no mobility restrictions and their treatment is mostly non-surgical. At $0.7 \%$, the percentage of patients who had surgery for TMD over the 1-year period observed in this study was also very low. The code K076 was more common, and we speculate that the $\mathrm{K}$ (disease) code was more common than the $\mathrm{S}$ (injury) code, as TMD is not an acute or fatal disease but rather a chronic condition that varies over time. ${ }^{9}$

Regarding the age of TMD patients, the highest percentage of patients were in their 20s for both the number of patients and the number of claims. The result showing that the prevalence of TMD decreases with age 


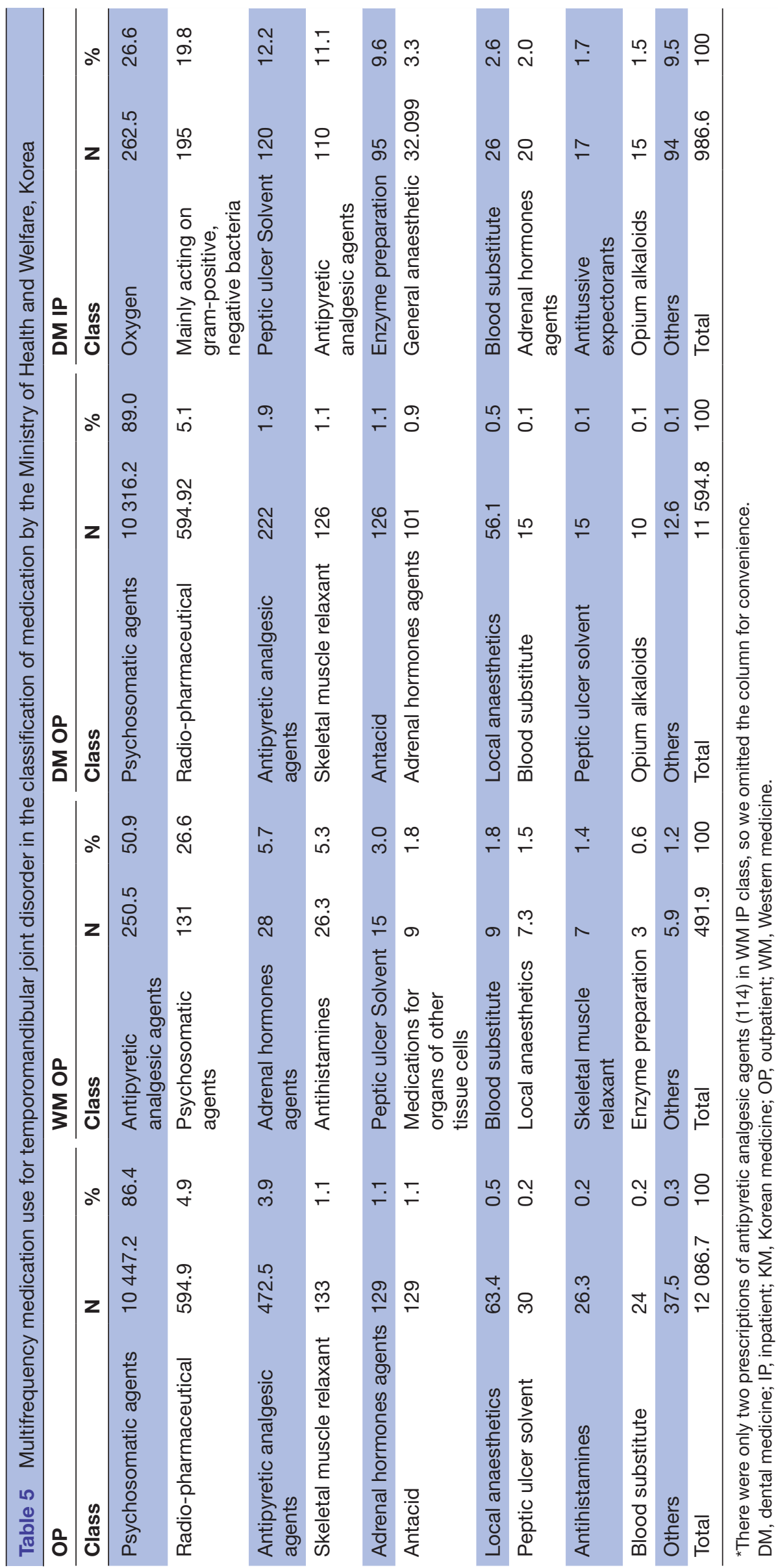


is in line with a previous finding. ${ }^{24}$ However, it is worth noting that the average number of days in care was higher among patients aged $\geq 50$ years than among their younger counterparts. The exact reason for the higher incidence of TMD among women is unclear; however, some studies suggest that it is related to hormones. ${ }^{25-27}$ One study reported an elevated oestrogen level in TMD patients; ${ }^{28}$ however, no study has empirically identified a relationship between hormones and TMD.

In Korea, the healthcare system is broadly classified into Korean and Western medicine, excluding dental medicine, and this study is the first to investigate the status of TMD care in Korea including Korean medicine care. Our results showed that as of 2017, dental care in Korea was more commonly sought than Western or Korean medicine care for TMD treatment. This is consistent with previous results using the HIRA data set from 2003 to $2005 .{ }^{14}$ After excluding dental medicine outpatients, Western and Korean medicine outpatients accounted for $9.8 \%$ and $8.2 \%$ of patients, respectively, and in terms of total visit count, Korean medicine outpatient visits accounted for the second highest percentage of visits following dental medicine outpatient visits.

Consultation fees accounted for the greatest percentage in both frequency and expense. Consultation is the most basic and frequently provided healthcare service. In a study that examined the status of cervical disorders using the HIRA-NPS data set, consultation fees accounted for the greatest percentage of medical cost. ${ }^{22}$ Radiographic evaluation and intervention fees were the second highest in frequency and cost, showing that diagnostic testing is important in the care of TMD patients. When we compared dental and Western medicine only, there were more claims in dental medicine. In Western medicine, most claims were for physiotherapy; however, there were more expenses for treatment and surgery in dentistry. Whereas the frequency of treatment (and surgery fee claims) was 24 (147.9 US\$) in Western medicine, it was 17624 (101 226.9 US\$) in dental medicine, suggesting that most surgical treatments were performed in dentistry. Further, because Korean medicine doctors currently face restrictions in using diagnostic devices, there were no claims for radiographic evaluation and intervention in Korean medicine. Due to the nature of Korean medicine care, fees for treatment and surgery and those for physiotherapy were also excluded in Korean medicine claims. Because acupuncture and cupping therapy fees are generally claimed in Korean medicine, claims for injection and non-surgical intervention accounted for the majority of covered benefits in Korean medicine (in both frequency and total cost).

As TMD patients are seldom hospitalised and rarely undergo surgery, hospitalisation and anaesthesia fees accounted for only a small proportion of medical expenditures. Medication fees also accounted for a small proportion, which shows that pharmacological treatment is relatively rare for TMD patients.

We examined the usual care that was mostly performed on TMD patients by dividing the sample into recipients of outpatient and inpatient care. TMJ stimulation in dental medicine was the most frequently performed outpatient care $(51.1 \%)$, and this can be considered the most basic care for TMD. TMJ stimulation refers to various treatments performed to treat TMD, and it encompasses a wide category of treatments such as superficial heat therapy, deep heat therapy, transcutaneous electrical nerve stimulation, low-frequency stimulation, myomonitor, silver spike point therapy, TMD exercise therapy, rehabilitative low-level laser therapy and myofascial trigger point injection. Because the same code can be used for different treatments and the same treatment can be classified into various codes, it can be difficult to assess physiotherapies by categorising them by their treatment codes. To examine the current state in more detail, treatment codes need to be revised. Superficial heat, deep heat and rehabilitative low-level laser therapies that have been frequently performed in Western medicine outpatient care can also be construed as physiotherapies overlapping with TMJ stimulation.

The second-most frequently performed treatment in outpatient care was general acupuncture (19.9\%), which is only performed in Korean medicine. It is also the most commonly performed treatment in both inpatient and outpatient Korean medicine care. This shows that acupuncture therapy is the major treatment for TMD among covered Korean medicine care, and evidence for using acupuncture for TMD has been confirmed by multiple randomised controlled trials. ${ }^{29-31}$ Surgery was only performed in dental medicine, and the rates of surgery were $0.12 \%$ and $10.7 \%$ in all outpatient and inpatient care, respectively, showing conservative treatment as the usual care for TMD patients, and that the surgery rate was higher among inpatients than among outpatients. According to our results, TMJ arthrocentesis was the only surgery code claimed in 2017. It seems to have been commonly performed on TMD patients in need of surgical treatment, as it is a relatively simple technique that can be performed as an alternative to a more invasive surgery. ${ }^{32}$ Blocking of the cranial nerve or its peripheral branch in Western medicine outpatient care was the most often performed injection/non-surgical intervention. Many studies have reported that the tenderness of the masticatory muscles is the most consistent symptom related to TMD discovered during examination, ${ }^{33-36}$ which is why subcutaneous or intramuscular injections are frequently administered. Blocking of the cranial nerve or its peripheral branch was rarely performed in dental medicine, suggesting that it is generally performed in Western medicine as opposed to in dentistry. Occlusal adjustment was the most common procedure in dentistry. Hot and cold meridian therapy was the second most common, as it is often combined with acupuncture therapy as a type of Korean medicine physiotherapy.

Drugs most often prescribed for TMD in outpatient care were psychosomatic drugs $(86.4 \%)$, followed by radiopharmaceuticals and antipyretic analgesic agents. Systematic reviews suggest that non-steroidal anti-inflammatory 
drugs, acetaminophen, diazepam, hyaluronate, glucocorticoid, tricyclic antidepressants (TCAs) and antiepileptic drugs may be effective for treating TMD pain. However, studies specifically comparing the effects of these drugs on TMD are limited, and adequate guidelines for pharmacotherapy are lacking. ${ }^{37}{ }^{38}$ In the only study that investigated the state of medications for TMD by drug group in Korea, ${ }^{14}$ the most often prescribed drugs for outpatients from 2003 to 2005 were antipyretic analgesic agents (54.9\%), psychosomatic drugs (20.4\%) and skeletal muscle relaxants $(17.5 \%)$. Although the order of frequency in that study differs from our findings, we observed that analgesics and psychosomatic drugs were generally used in the usual care of TMD.

According to our results, psychosomatic drugs were most frequently used in 2017, and diazepam was particularly most frequently prescribed. Diazepam is most widely used for anxiety disorders but is also known to be effective on muscle spasms. ${ }^{39}$ Although the reason for its efficacy in TMD treatment has yet to be determined, it may be due to alleviation of underlying anxiety and spasm of muscles during mastication. ${ }^{40}$ The TCA amitriptyline, the second-most frequently prescribed medication, is also known to be effective for muscle contraction and musculoskeletal pain. ${ }^{41}$ Despite the efficacy of psychosomatic drugs, not many studies have recommended them as first-line medications for TMD, and further research is needed to substantiate their long-term effects and safety in TMD patients. The reason for such a change in trend is unknown, but it may suggest an association between TMD and psychiatric symptoms. Prior research has shown that chronic TMD is accompanied by psychiatric or mind-body diseases such as depression or somatisation disorder. ${ }^{42}$ This is consistent with the findings of previous studies stating that comprehensive psychosocial intervention involving psychological treatment such as cognitive behavioural therapy, posture regulation and biofeedback produces better outcomes than do traditional dental care. $^{43}$

The most frequent prescription among inpatients was oxygen, followed by antibiotics. Although there are no previous reports on the administration of these drugs in TMD patients, there is a possibility that these were administered due to an accompanying infectious disease or following a surgical procedure such as arthrocentesis. Although a prior study reported that antibiotics were administered to prevent infection after arthrocentesis, ${ }^{44}$ it is difficult to conclude that antibiotic administration is related to surgery, as the number of days of antibioticrelated medication use was markedly lower in outpatients. Furthermore, this value is not an accurate representation of the administration of these medications, because there was only a small number of inpatients.

\section{Limitations}

This study has several limitations. First, it may be difficult to accurately classify TMD using the diagnostic classifications for reimbursement. The HIRA-NPS includes data submitted to receive compensation from the national payer only in areas where the purpose is covered by the NHI. Therefore, there may be a difference between the diagnosis submitted by medical service providers (doctors) for reimbursement and the actual diagnosis for the patient. This may be due to either underreporting or coding of conditions that did not exist (ie, upcoding) in order to receive a large amount of doctor's fee under the Korean fee-for-service system. Because we operationally defined TMD in this study, defining TMD patient groups solely based on diagnosis would diminish the accuracy. However, because the diagnostic accuracy of the HIRA-NPS claims is on average about $70 \%,{ }^{45}$ it has little effect on our findings. Therefore, subsequent studies utilising claims data should pay close attention to diagnostic accuracy. It has been reported that diagnosis is more accurate for inpatients, severely ill patients and patients in general/tertiary hospitals than it is for outpatients, patients with frequently mild diseases and patients in clinics, respectively. ${ }^{45}$ Furthermore, we used the data of patients who were assigned corresponding diagnostic codes. However, it is possible that the data set included patients who had been assigned an incorrect code or excluded patients due to misdiagnosis. Second, adherence to outpatient prescriptions was unknown, as there was no way to confirm whether the patients actually took the drugs. This is a limitation common to all claims data. Third, non-covered care and over-the-counter drugs were not included in claims data, as they are not claimed for payment. In this study, treatments such as intraoral occlusion appliance, ${ }^{46}$ botulinum toxin injection ${ }^{47}$ and pharmacoacupuncture, ${ }^{48}$ among others, were not included. In particular, herbal medicine is generally prescribed as a non-covered prescription; thus, we were limited in our analysis on the drug prescriptions in Korean medicine. Furthermore, due to the limited number of inpatients included in the data set, detailed analysis of inpatient data was difficult. Therefore, our analysis is not representative of the entire patient population. Finally, this was a cross-sectional study analysing data over a 1-year period, so long-term follow-up was impossible. Future studies should use cohort claims data to additionally examine the natural course of the disease.

\section{CONCLUSIONS}

This study analysed the current medical expenditures and usual care for TMD using the 2017 HIRA claims data. Our findings showed that patients with TMD visited the hospital visit 2.4 times a year and spent 29.7 US\$ per case as outpatients. Outpatient visit expenses accounted for the greatest proportion of all expenditures $(35.4 \%)$, followed by treatment and surgery $(20.5 \%)$, radiographic evaluation/intervention $(18.1 \%)$ and injection/non-surgical intervention (16.3\%). TMJ stimulation $(51.1 \%)$ and acupuncture (19.9\%) were most frequently performed in usual care practices, while psychosomatic drugs $(86.4 \%)$ were the. The most commonly prescribed drugs in overall 
care and in dental outpatient care. Considering the lack of research comparing patients with TMD in terms of Western medicine, dental medicine and medicine, dental medicine, Korean medicine, we believe our study is the first study to investigate the current status of TMD in Korea at the national level. We also believe our findings will provide useful information about the diversity of therapies for TMD and the corresponding costs incurred in the treatment of TMD. Our results regarding the distribution of medical costs for the treatment of relevant diseases can be used as evidence for making important health policy decisions such as the determination of health insurance fees and budgeting.

Contributors Conceptualisation and investigation: HS, BJ, I-HH. Data curation and formal analysis: BJ, JY. Methodology, project administration and supervision: BJ, I-HH. Validation: K-WK, J-HC, YJL.

Funding This work was supported by a grant from the Traditional Korea Medicine R\&D Program through the Korea Health Industry Development Institute (KHIDI), funded by the Ministry of Health and Welfare, Republic of Korea (grant number: HB16C0059). The study design, execution, analysis and interpretation of data and reporting of results will be conducted separately from the funding source.

Competing interests None declared.

Patient consent for publication Not required.

Ethics approval The study was approved by the Institutional Review Board of Jaseng Hospital of Korean Medicine in Seoul, Korea (JASENG 2019-05-007), and was performed in accordance with the principles expressed in the Declaration of Helsinki. Because the study analysed publicly available data, the need for informed consent was waived. All personal information was deidentified by the NHIS prior to public release.

Provenance and peer review Not commissioned; externally peer reviewed.

Data availability statement Data are available in a public, open access repository. Data are available upon reasonable request. The data sets generated during and/ or analysed in the current study are available in the HIRA-NPS repository. The study utilised HIRA data, which are third-party data and thus not owned by the authors. The HIRA data are available upon direct request, via email or fax and submission of the request form and declaration of data use, which are downloadable from the HIRA website (http://opendata.hira.or.kr/op/opc/selectPatDataApllnfoView.do), and upon payment of a data request fee (300 000 KRW per data set).

Supplemental material This content has been supplied by the author(s). It has not been vetted by BMJ Publishing Group Limited (BMJ) and may not have been peer-reviewed. Any opinions or recommendations discussed are solely those of the author(s) and are not endorsed by BMJ. BMJ disclaims all liability and responsibility arising from any reliance placed on the content. Where the content includes any translated material, BMJ does not warrant the accuracy and reliability of the translations (including but not limited to local regulations, clinical guidelines, terminology, drug names and drug dosages), and is not responsible for any error and/or omissions arising from translation and adaptation or otherwise.

Open access This is an open access article distributed in accordance with the Creative Commons Attribution Non Commercial (CC BY-NC 4.0) license, which permits others to distribute, remix, adapt, build upon this work non-commercially, and license their derivative works on different terms, provided the original work is properly cited, appropriate credit is given, any changes made indicated, and the use is non-commercial. See: http://creativecommons.org/licenses/by-nc/4.0/.

\section{ORCID iDs}

Boyoung Jung http://orcid.org/0000-0001-9812-0745

Yoon Jae Lee http://orcid.org/0000-0002-1532-0942

In-Hyuk Ha http://orcid.org/0000-0002-5020-6723

\section{REFERENCES}

1 Kwon YD, Lim YE, Song YS. Relationship between temporomandibular joint (TMJ) disorder and meridian. J Oriental Rehab Med 2000;10:1.
2 Korean Society of Chuna manual Medicine for Spine \& Nerves. Chuna manual medicine. Seoul: Korean Society of Chuna manual Medicine for Spine \& Nerves, 2011: 447-8.

3 Stechman-Neto J, Porporatti AL, Porto de Toledo I, et al. Effect of temporomandibular disorder therapy on otologic signs and symptoms: a systematic review. J Oral Rehabil 2016;43:468-79.

4 Fricton JR, Kroening RJ, Hathaway KM. TMJ and craniofacial pain: diagnosis and management. Ishiyaku EuroAmerica 1988.

5 de Godoi Gonçalves DA, Dal Fabbro AL, Campos JA, et al. Symptoms of temporomandibular disorders in the population: an epidemiological study. J Orofac Pain 2010;24.

6 Drangsholt MT, LeResche L. Temporomandibular disorder pain. In: Crombie IK, Croft PR, Linton SJ, eds. Epidemiology of pain. IASP Press Seattle, 1999.

$7 \mathrm{Sim} \mathrm{S-H,} \mathrm{Ha} \mathrm{M.} \mathrm{Association} \mathrm{between} \mathrm{psychological} \mathrm{factors} \mathrm{and}$ temporomandibular disorders in Korean adults : The fouth Korean national health and nutritional examination survey(2009). J Korean Soc Dent Hyg 2013;13:739-47.

8 Highest prevalence of temporomandibular disorders among women in their 20S. Available: http://www.mohw.go.kr/react/al/sal0301vw. jsp?PAR_MENU_ID=04\&MENU_ID=0403\&CONT_SEQ=331226\& page $=36$ [Accessed 04 Apr 2020].

9 Hong J. Diagnosis and treatment of temporomandibular joint disorders. Clin J Pain 2005;4:55-66.

10 Visscher CM, Ligthart L, Schuller AA, et al. Comorbid disorders and sociodemographic variables in temporomandibular pain in the general Dutch population. J Oral Facial Pain Headache 2015;29:51-9.

11 Mundt T, Mack F, Schwahn C, et al. Association between sociodemographic, behavioral, and medical conditions and signs of temporomandibular disorders across gender: results of the study of health in Pomerania (SHIP-0). Int J Prosthodont 2008;21:141.

$12 \mathrm{Kim}$ T-Y, Shin J-S, Lee J, et al. Gender difference in associations between chronic temporomandibular disorders and general quality of life in Koreans: a cross-sectional study. PLoS One 2015;10:e0145002.

13 Shimshak DG, Kent RL, DeFuria M. Medical claims profiles of subjects with temporomandibular joint disorders. Cranio 1997;15:150-8.

14 Yang HY, Kim ME. Prevalence and treatment pattern of Korean patients with temporomandibular disorders. J Oral Med Pain 2009;34:63-79.

15 Kim L, Kim J-A, Kim S. A guide for the utilization of health insurance review and assessment service national patient samples. Epidemiol Health 2014;36:e2014008.

16 Guidance on patient sample data access request Health insurance review \& assessment service. Available: http://opendata.hira.or.kr/op/ opc/selectPatDataApllnfoView.do [Accessed 04 Apr 2020].

17 Fujiwara K, Imanishi J, Watanabe S, et al. Changes in attitudes of Japanese doctors toward complementary and alternative medicinecomparison of surveys in 1999 and 2005 in Kyoto. Evid Based Complement Alternat Med 2011;2011:1-7.

18 Ryu J, Choi B, Lim B, et al. Medical practices and attitudes of duallicensed medical doctors in Korea. Evid Based Complement Alternat Med 2013:2013:1-7.

19 Bueno CH, Pereira DD, Pattussi MP, et al. Gender differences in temporomandibular disorders in adult populational studies: a systematic review and meta-analysis. J Oral Rehabil 2018;45:720-9.

20 lodice G, Cimino R, Vollaro S, et al. Prevalence of temporomandibular disorder pain, jaw noises and oral behaviours in an adult Italian population sample. J Oral Rehabil 2019;46:691-8.

21 Welfare(MOHW), M.o.H.a. Home page of Ministry of Health and Welfare(MOHW). [cited 2020 June 30], 2020. Available: http://www. mohw.go.kr/eng/hs/hs0101.jsp?PAR_MENU_ID=1006\&MENU_ID= 100601

22 Choi AR, Shin J-S, Lee J, et al. Current practice and usual care of major cervical disorders in Korea: a cross-sectional study of Korean health insurance review and assessment service national patient sample data. Medicine 2017;96:e8751.

23 De Rossi SS, Greenberg MS, Liu F, et al. Temporomandibular disorders: evaluation and management. Med Clin 2014;98:1353-84.

24 Carlsson GE, Magnusson T. Management of temporomandibular disorders in the general dental practice. Postgraduate textbook. Quintessence, 2000.

25 Abubaker AO, Raslan WF, Sotereanos GC. Estrogen and progesterone receptors in temporomandibular joint discs of symptomatic and asymptomatic persons: a preliminary study. J Oral Maxillofac Surg 1993;51:1096-100.

26 Milam SB, Aufdemorte TB, Sheridan PJ, et al. Sexual dimorphism in the distribution of estrogen receptors in the temporomandibular joint complex of the baboon. Oral Surg Oral Med Oral Pathol 1987;64:527-32. 
27 Aufdemorte TB, Van Sickels JE, Dolwick MF, et al. Estrogen receptors in the temporomandibular joint of the baboon (Papio cynocephalus): an autoradiographic study. Oral Surg Oral Med Oral Pathol 1986;61:307-14.

28 Scrivani SJ, Keith DA, Kaban LB. Temporomandibular disorders. N Engl J Med 2008;359:2693-705.

29 List T, Helkimo M, Andersson S, et al. Acupuncture and occlusal splint therapy in the treatment of craniomandibular disorders. Part I. A comparative study. Swed Dent J 1992;16:125-41.

30 Johansson A, Wenneberg B, Wagersten C, et al. Acupuncture in treatment of facial muscular pain. Acta Odontol Scand 1991;49:153-8.

31 Raustia AM, Pohjola RT, Virtanen KK. Acupuncture compared with stomatognathic treatment for TMJ dysfunction. Part I: a randomized study. J Prosthet Dent 1985;54:581-5.

32 Brennan PA, llankovan V. Arthrocentesis for temporomandibular joint pain dysfunction syndrome. J Oral Maxillofac Surg 2006;64:949-51.

33 Lipton JA, Ship JA, Larach-Robinson D. Estimated prevalence and distribution of reported orofacial pain in the United States. J Am Dent Assoc 1993;124:115-21.

34 Schiffman EL, Fricton JR, Haley DP, et al. The prevalence and treatment needs of subjects with temporomandibular disorders. J Am Dent Assoc 1990;120:295-303.

35 Kurita K, Westesson PL, Yuasa H, et al. Natural course of untreated symptomatic temporomandibular joint disc displacement without reduction. J Dent Res 1998;77:361-5.

36 Rammelsberg P, LeResche L, Dworkin S, et al. Longitudinal outcome of temporomandibular disorders: a 5-year epidemiologic study of muscle disorders defined by research diagnostic criteria for temporomandibular disorders. J Orofac Pain 2003;17:9-20.

37 List T, Axelsson S. Management of TMD: evidence from systematic reviews and meta-analyses. J Oral Rehabil 2010;37:430-51.
38 Mujakperuo HR, Watson M, Morrison R, et al. Pharmacological interventions for pain in patients with temporomandibular disorders. Cochrane Database Syst Rev 2010:CD004715.

39 Calcaterra NE, Barrow JC. Classics in chemical neuroscience: diazepam (valium). ACS Chem Neurosci 2014;5:253-60.

40 Pramod GV, Shambulingappa P, Shashikanth MC, et al. Analgesic efficacy of diazepam and placebo in patients with temporomandibular disorders: a double blind randomized clinical trial. Indian J Dent Res 2011;22:404.

41 Kreisberg MK. Tricyclic antidepressants: analgesic effect and indications in orofacial pain. J Craniomandib Disord 1988;2:171-7.

42 Yap AUJ, Tan KBC, Chua EK, et al. Depression and somatization in patients with temporomandibular disorders. J Prosthet Dent 2002;88:479-84

43 Sherman JJ, Turk DC. Nonpharmacologic approaches to the management of myofascial temporomandibular disorders. Curr Pain Headache Rep 2001;5:421-31.

44 Nishimura M, Segami N, Kaneyama K, et al. Prognostic factors in arthrocentesis of the temporomandibular joint: evaluation of 100 patients with internal derangement. J Oral Maxillofac Surg 2001;59:874-7.

45 Park B, Seong J, Park G, et al. Studying on improving diagnosis codes in national health insurance claims data. Seoul: Health Insurance Review Assessment Service, 2003.

46 List T, Jensen RH. Temporomandibular disorders: old ideas and new concepts. Cephalalgia 2017;37:692-704

47 Schwartz M, Freund B. Treatment of temporomandibular disorders with botulinum toxin. Clin J Pain 2002;18:S198-203.

$48 \mathrm{Kim} \mathrm{C}-\mathrm{E}$, Do H-J, Song H-S, et al. A web-based survey for assessment of Korean medical treatment clinical practice patterns for temporomandibular disorders. J Korean Med Rehabil 2018;28:73-84. 